Boris Filipović-Grčić ${ }^{1}$

\title{
PREHRANA NEDONOŠČETA I NEDOSTAŠČETA
}

\section{Pregledni članak}

Sažetak: Jedan od najvećih problema suvremene neonatologije je liječenje nedonoščadi i djece s IUZR-om. Ova skupina djece ima veću smrtnost i akutno pobolijevanje, te lošije udaljene ishode i neurorazvoj nego terminska i djeca koja su rodne mase odgovajuće za dob trudnoće. Odgovarajući somatski rast odnosno dobivanje na težini ove djece prate i bolji neurorazvojni ishodi. To je omogućilo da im optimiziranjem prehrane osiguramo bolji opći i neurorazvojni ishod.

Ključne riječi: nedonošče, intrauterini zastoj rasta, prehrana, neurorazvoj

Summary: The one of the largest challenges of the contemporary neonatology is the treatment of premature newborns and those with intrauterine growth restriction. Their mortality and morbidity as well as remote outcomes, particularly neurodevelopmental, are worse than in comparative populations. Better growth and weight gain are followed by better neurodevelopmental outcomes. Optimization of their feeding could improve their general and neurodevelopmental outcomes.

Key words: premature infant, intrauterine growth restriction, feeding, neurodevelopment

\section{Uvod}

Poznato je da je prehrana zdravog terminskog novorođenčeta majčinim mlijekom (MM) najbolja pa se stoga i naziva prirodnom prehranom. Prehrana nedonoščadi i nedostaščadi ima svoje specifičnosti s obzirom na kratko trajanje trudnoće i dodatnu patologiju nedostaščadi pa će se razmotriti osnovne značajke ovih stanja.

1 Zavod za neonatologiju i neonatalnu intenzivnu medicinu, Klinika za pedijatriju KBC Zagreb i Medicinskog fakulteta Zagreb; borisfilipovicgrcic@gmail.com 


\section{Nazivlje i epidemiologija nedonoščadi i nedostaščadi}

Definicija nedonoščeta je jasna, dok se uz ,nedostašče“ mogu vezati određena nerazumijevanja. Nerijetko se pojmovi „mali za gestacijsku dob“ (engl. small for gestational age - SGA) i ,intrauterini zastoj rasta“ (IUZR) koriste kao sinonimi, no oni to nisu. Pojam novorođenčeta SGA odnosi se na one koji su rodnom masom (RM) ispod 10. percentile za određenu dob trudnoće (DT) (1), i to neovisno o uzroku koji je do toga doveo. Intrauterini (fetalni) zastoj rasta (IUZR) označava pojavu usporenja intrauterinog rasta kao i onu novorođenčad koja je rođena s kliničkim znacima pothranjenosti, neovisno o poziciji na percentilnim krivuljama rasta. IUZR je definiran kao patološki uzrokovano usporenje fetalnog rasta radi kojeg fetus ne može dosegnuti svoj potencijal (2). Smatra se da se smanjena RM nađe u oko $10 \%$ sve novorođenčadi i većinom se radi o djeci SGA bez podležeće patologije, a razlikovanje ove i djece $s$ IUZR-om nije uvijek jednostavno (3).

\section{Utvrdivanje doraslosti za dob trudnoće i intrauterinog zastoja rasta}

Procjenjivanje fetalnog rasta daje nam važne informacije o odnosu trudnice, posteljice i fetusa te ukazuje na ishod trudnoće. Novorođenče čija će RM biti ispod 10. percentile za pripadajuću DT ćemo proglasiti SGA pa ovako postavljanje dijagnoze možemo smatrati jednostavnim, no ne govori o uzroku koji je doveo do usporenja fetalnog rasta. Porodničar će praćenjem fetalnog prirasta utvrditi dijagnozu IUZR-a.

\section{Podjela tipova IUZR-a}

Postoje dva odnosno tri tipa IUZR-a: asimetrični ili IUZR uzrokovan pothranjenošću, simetrični ili hipoplastični i treći tip, miješani IUZR (4).

Simetrični oblik IUZR-a je rjeđi, nalazi se u oko $20-30 \%$ djece. Za razliku od asimetričnog IUZR-a, sve su dimenzije fetusa smanjene proporcionalno (5). Njihova je prognoza s obzirom na najčešće uzroke sporijeg rasta (intrauterine infekcije i genetski poremećaji) dubioznija nego za djecu s asimetričnim IUZR $(6,7)$. Asimetrični oblik IUZR-a je češći, nalazi se u 70-80\% sve djece s IUZR-om. Najčešći uzrok je utero-placentalna insuficijencija. Prenatalno se uočava smanjenje opsega trbuha dok je veličina glave i dužina femura očuvana. To ovoj djeci daje specifičan izgled malnutricije - glava je velika u usporedbi s tijelom koje je normalne dužine, ali mršavo, dajući dojam ispaćenosti, no njihova je prognoza bolja od djece sa simetričnim oblikom IUZR-a.

\section{Etiologija i patogeneza IUZR-a}

Uzroci IUZR-a mogu potjecati od majke, fetusa, placentalnih činitelja, ali i kombinacije navedenih. 
Najčešći (70\%) su maternalni uzroci IUZR-a: dob, nizak socioekonomski status, anamneza prethodne djece s IUZR-om ili nekom drugom težom patologijom trudnoće, medikacija specifičnim lijekovima (citostatici, antiepileptici), zloporaba opojnih tvari, primjena metoda pomognute oplodnje, prekratko ili predugo razdoblje između trudnoća, slabo korištenje medicinske skrbi prije i tijekom trudnoće, preeklampsija, kronične bolesti majke, dijabetes kompliciran vaskulopatijom, pretjerana, ali i smanjena tjelesna masa, naporan fizički rad, majčino gladovanje, slabo dobivanje na masi tijekom trudnoće, infekcije, malformacije spolnih organa majke, te patološka stanja trudnoće (4).

Placentalni uzroci IUZR-a potječu od insercije pupkovine i anatomije krvnih žila, hematoma i infarkta posteljice, placentalne insuficijencije, preeklampsije, trombofilije, abrupcije posteljice i infekcija. Višeplodne trudnoće sa i bez uzajamne blizanačke transfuzije također pridonose pojavi IUZR-a.

Najčešći fetalni uzroci IUZR-a su prirođene malformacije, genski defekti, prirođene metaboličke bolesti te višeplodne trudnoće i infekcije (4).

\section{Smrtnost i pobolijevanje novorođenčadi malene za dob trudnoće i novoro- đenčadi s IUZR-om}

Poznato je da su smrtnost i pobolijevanje novorođenčadi sve veći uz kraću DT i uz nižu RM.

Novorođenčad koja je manja za DT u usporedbi s onom terminskom, a odgovarajuće mase za DT, ima veću smrtnost i pobolijevanje (8). Nakon nedonošenosti, IUZR je drugi najučestaliji uzrok pobolijevanja (7) i umiranja (10-20 puta više) u usporedbi s onom koja su odgovarajuće RM za DT (9).

Fetus s IUZR-om prenatalno raste usporeno jer ne dobiva dovoljno prehrambenih tvari te krvotokom usmjerava svoje nutrijente u najvažnija područja - mozak, srce, nadbubrežnu žlijezdu i povećava koncentraciju eritrocita. Takvo će dijete imati smanjenu mišićnu masu i masu bjelančevina, te manju količinu masti i mineralni sadržaj kosti. Koncentracija glukoze i insulina će biti smanjena pa će posljedično i količina glikogena biti manja. Razne metaboličke prilagodbe u cilju preživljavanja fetusa u uvjetima usporena intrauterinog rasta mogu stvoriti podlogu za razvoj niza poremećaja i bolesti u novorođenačkoj, dječjoj i odrasloj dobi (10), usporen rast tijekom djetinjstva i nižu konačno dosegnutu visinu, pretilost, hipertenziju, koronarnu bolest i dijabetes tip 2 (11).

Djeca s IUZR-om će imati veću učestalost prijevremenog poroda, perinatalne asfiksije, tranzicijskih problema, konvulzija, intrakranijalnog krvarenja, periventrikularne leukomalacije, hipoksičko-ishemičke encefalopatije, mekonijskog aspiracijskog sindroma, perzistentne plućne hipertenzije, hipoglikemije, hipokalcemije, problema $\mathrm{s}$ termoregulacijom, nekrotizirajućeg enterokolitisa, bronhopulmonalne displazije, 
retinopatije nedonoščadi, kolestaze, policitemije, poremećene prirođene imunosti, sepse. Duže će boraviti u bolnici uz veće troškove liječenja (10).

Šansa za nastup cerebralne paralize je u djece s IUZR-om i šest puta veća nego u onih s odgovarajućom RM. Druge neurorazvojne teškoće su u ove djece također češće: slabiji kognitivni razvoj, poremećaji pažnje, slabiji akademski dosezi, slabije socijalne vještine (7). Djeca s IUZR-om, posebice ukoliko su rođena prije roka, imaju manji volumen mozga, volumen sive moždane tvari i hipokampalne regije, što traje do u djetinjstvo utječući na slabije rezultate neurorazvojnih ispitivanja. Nedonoščad s IUZR imaju značajno manju masu korteksa ubrzo po porodu, ali i u očekivanom terminu poroda (12). Još nisu jasni točni načini utjecaja IUZR-a na lošiji neurorazvojni ishod ove djece, no u animalnim istraživanjima pokazano je da intrauterina hipoksemija i malnutricija te povišena koncentracija kortizola mogu igrati važnu ulogu.

\section{Liječenje djece s IUZR-om}

Liječenje nedonoščadi i djece s IUZR-om je najznačajniji zdravstveni problem s kojim se susreće suvremena neonatologija. Porode ovakve djece treba koncentrirati u neonatalnim jedinicama intenzivnog liječenja radi njihova zahtjevnijeg nadzora i liječenja svih naprijed spomenutih problema. Izgleda da nema dvojbi da je nutritivno liječenje važan dio liječenja ove djece te da se ispravnom prehranom može značajno utjecati na njihov neposredni i kasniji ishod, vodeći računa posebno o neurorazvoju (13). Dokazano je da su neurorazvojni deficiti veći u djece koja su slabije napredovala na težini za vrijeme boravka u bolnici pa se optimiziranjem prehrane može postići najbolji neurorazvojni ishod u ove djece (14).

\section{Prehrana nedonoščadi i nedostaščadi}

Fetus je do rođenja prehranjivan parenteralnim putem i to u količini koja mu je omogućila brzi, pa i najbrži mogući rast. Potrebe za nutrijentima i energijom ne prestaju nego se nastavljaju nakon rođenja, $\mathrm{s}$ dodatnom potrebom održavanja vlastite termoregulacije, dinamičke potrošnje energije na probavu, disanje, spontanu motoriku, te na rast, pa su prehrambene potrebe ove djece veće nego u kasnijoj dobi.

\section{Parenteralna prehrana}

Mnogu od ove djece, posebice onu izrazito male RM i izrazito kratka trajanja trudnoće neće biti moguće hraniti od početka punim enteralnim unosom nego će im se prehrambene potrebe zadovoljavati parenteralno. 
Parenteralna prehrana (PP) upravo pomaže dosegnuti puni enteralni unos time što „kupuje vrijeme“ $u$ kojem će se volumen želuca prilagoditi potrebama i obrocima djeteta, a uz postizanje optimalnog rasta bez istovremenog nastupa intolerancije hrane (15). Idealan je cilj postići takav postnatalni rast nedonoščadi koji će pratiti njihovu krivulju prenatalnog rasta, što je međutim teško dohvatljivo. Štoviše, neodgovarajuća prehrana u prvim danima i tjednima života će za posljedicu imati odgođen povratak mase na RM te usporen postnatalni rast s nepovoljnim posljedicama na neurorazvoj djece (16).

Glukoza je glavni izvor energije i dozira se u udjelu $35-50 \%$ kalorija. Uobičajeno se počinje infuzijom u dozi od $5-8 \mathrm{mg} / \mathrm{kg} \mathrm{TT} / \mathrm{min}$ i povećava se do $12 \mathrm{mg} / \mathrm{kg} / \mathrm{min}$. Veći unos glukoze povećava deponiranje masti i pojavu steatoze jetre te povećava proizvodnju ugljičnog dioksida. Rana primjena glukoze i proteina brzo omogućuje retenciju dušika (16). Važno je nadzirati glikemiju, posebice u manje nedonoščadi radi veće sklonosti hiperglikemiji.

Ukoliko se ne nadoknađuju proteini, dnevni gubitak vlastitih proteina je oko 0,5 - 1,2 g/kg TT. Za optimalnu ugradnju proteina važno je ostvariti dovoljnu količinu energije i to: za dijete TT $1-1,8 \mathrm{~kg}: 3,2-3,6 \mathrm{~g} / 100 \mathrm{kcal}$, a za dijete TT $<1 \mathrm{~kg}: 3,6$ $-4,1 \mathrm{~g} / 100 \mathrm{kcal}$. Ukupan proteinski unos ne bi trebao biti veći od $16 \%$ potrebnih kalorija. Preporučljivo je nedonoščadi započeti proteinskim unosom od 2,5 g/kg TT već od prvog dana života, te povećati na $3,5 \mathrm{~g} / \mathrm{kg}$, a po nekima i više, do $4,4 \mathrm{~g} / \mathrm{kg} /$ dan do trećeg dana života.

Unosom lipidnih emulzija zadovoljava se potreba za esencijalnim masnim kiselinama - linolnom i linolenskom. Optimalan unos masti će zadovoljiti $40-50 \%$ kalorijskih potreba. Primjenjuje se $20 \%$ emulzija koja sadrži sojino, maslinovo i riblje ulje te ulje srednjolančanih triglicerida. Uobičajeno se lipidi počinju primjenjivati prvog dana života u dozi od $1 \mathrm{~g} / \mathrm{kg}$ TT, te se unos postupno povećava do $3 \mathrm{ili} 4 \mathrm{~g} / \mathrm{kg}$ TT.

Doprema energije treba zadovoljiti uobičajene potrebe bazalnog metabolizma nedonoščadi (50-75 kcal/kg/dan, u što se ubraja dinamička potrošnja (oko 5-8\%) i gubitci stolicom (oko 10\%), te povrh toga i potrebe za rast (apsorpciju, metabolizam i ugradnju novih molekula bjelančevina i masti u tkiva djeteta - oko $25-45 \mathrm{kcal} / \mathrm{kg} /$ dan). Ukupne se potrebe nedonoščadi za energijom kreću od 85 do $140 \mathrm{kcal} / \mathrm{kg} / \mathrm{dan}$.

\section{Enteralna prehrana}

Parenteralnim putem premošćujemo potrebe do prelaska na isključivu enteralnu prehranu, stoga kad god je to moguće, što ranije, u svakog novorođenčeta započinjemo enteralnim hranjenjem.

U prvim danima života enteralnim putem se daju malene količine hrane, provodi se tzv. trofičko hranjenje. Optimalno je to MM. Radi nemogućnosti sisanja u najranijoj dobi izrazito malene nedonoščadi ovi se obroci daju putem gastričnog katetera. 
Volumen trofičkog hranjenja je $10-15 \mathrm{~mL} / \mathrm{kg}$ dnevno i pokazalo se da premda ne pridonosi nutritivnom učinku, u konačnici dovodi do sazrijevanja probavnog sustava nedonoščeta. To omogućuje ranije uvođenje potpune enteralne prehrane, smanjuje izloženost komplikacijama PP te skraćuje boravak u bolnici. Povećanje količine obroka se provodi vrlo individualizirano, od obroka do obroka. Procjenjivanje količine želučane retencije pred davanje sljedećeg obroka također je kontroverzno, kao i tumačenje ,prihvatljive“ količine retencije. Za prelazak s trofičke i djelomične na potpunu enteralnu prehranu je djeci $\mathrm{RM}<1000 \mathrm{~g}$ trebalo i do 35 dana.

\section{Majčino mlijeko}

Prehrana MM se smatra vrlo učinkovitom prevencijom NEC-a. Također su poznati i drugi povoljni učinci MM - bolji neurorazvojni rezultati i manja učestalost sepse. Kolonizacija djetetova probavnog sustava majčinim mikrobima, te dodatno sekretorni IgA, lizozim, laktoferin, interferon, sve povoljno djeluje na razvoj i funkciju probavnog sustava djeteta (17).

MM nedonoščadi je prvih tjedana bogatije proteinima (čak 1,6 g/100 mL) i krećući se prema očekivanom terminu ta se koncentracija smanjuje na oko $1 \mathrm{~g} / 100$ $\mathrm{mL}$. MM nedonoščeta je bogatije nekim mineralima, no još uvijek je taj i proteinski sastav nedovoljan da bi zadovoljio potrebe izrazito malenog nedonoščeta pa mu se mogu dodavati pojačivači. Pojačivačima osiguravamo dodatne bjelančevine, kalcij, fosfate, ugljikohidrate, vitamine i oligoelemente.

\section{Umjetna enteralna prehrana}

Ukoliko na raspolaganju nemamo MM, provodi se umjetna prehrana različitim pripravcima. Prematurni pripravci sadržavaju više proteina nego pripravci za terminsku djecu, oko 3, pa i 3,6 g/100 mL. Nedovoljan unos proteina će usporiti rast, ali i neurorazvoj nedonoščadi, posebice one najmanje, pa je važno pratiti unos proteina i rast djece. Izostanak rasta upozorava da će nastupiti i usporenje neurorazvoja. Većina masnoća prematurnih pripravaka su srednjelančani trigliceridi koji se lakše probavljaju, a dodaju se i dokozaheksanoična i arahidonska kiselina (dugolančane višestrukonezasićene masne kiseline) koje su od velikog značaja za razvoj mozga i retine (17).

\section{Postizanje rasta novorođenčeta}

Unatoč nastojanju postizanja optimalnog rasta koji će pratiti krivulju intrauterinog rasta i nakon poroda, većina najmanje nedonoščadi će ipak zaostajati u dobi od 36 tjedana postmenstrualne dobi. Na to utječu mnoga zbivanja tijekom početnog 
liječenja nedonošenosti (respiratorni distres sindrom, kronična plućna bolest, NEC, intrakranijalno krvarenje i sl.), ali se vidi i utjecaj primjene različitih količina proteina u prehrani (17). Nakon otpusta iz bolnice treba podmiriti još uvijek povećane potrebe za nutrijentima i energijom. Potrebe valja procjenjivati individualno prateći krivulje rasta da bi se rano uočila odstupanja od željenog plana. Budući da još postoje kontroverze oko načina kako djetetu nakon otpusta iz bolnice osigurati veću količinu nutrijenata i energije optimalno je posavjetovati se s neonatologom ili gastroenterologom-nutricionistom.

\section{Zaključak}

Nedonoščad i djeca s IUZR-om imaju veću smrtnost i akutno pobolijevanje, te lošije udaljene ishode i neurorazvoj nego terminska i djeca čija je RM odgovajuća DT. Dokazano je da odgovarajući somatski rast odnosno dobivanje na težini ove djece prate i bolji neurorazvojni ishodi pa im optimiziranje prehrane može osigurati bolji opći i neurorazvojni ishod.

\section{Literatura}

1. Battaglia FC, Lubchenco LO. A practical classification of newborn infants by weight and gestational age. J Pediatr. 1967;71(2):159-63.

2. Mandruzzato G, Antsaklis A, Botet F, Chervenak FA i sur. Intrauterine restriction (IUGR). J Perinat Med 2008;36(4):277-81.

3. Albu AR, Anca AF, Horhoianu VV, Horhoianu IA. Predictive factors for intrauterine growth restriction. J Med Life 2014;7:165-71.

4. Sharma D, Shastri S, Sharma P. Intrauterine Growth Restriction: Antenatal and Postnatal Aspects. Clin Med Insights Pediatr 2016 Jul 14;10:67-83. doi: 10.4137/CMPed.S40070.).

5. Platz E, Newman R. Diagnosis of IUGR: traditional biometry. Semin Perinatol 2008;32:140-147.).

6. Dashe JS, McIntire DD, Lucas MJ i sur. Effects of symmetric and asymmetric fetal growth on pregnancy outcomes. Obstet Gynecol 2000;96:321-7.

7. Walker DM, Marlow N. Neurocognitive outcome following fetal growth restriction. Arch Dis Child Fetal Neonatal Ed 2008;93:F322-F325.

8. Katz J, Lee AC, Kozuki N, et al. CHERG Small-for-Gestational-Age-Preterm Birth Working Group. Mortality risk in preterm and small-for gestational-age infants in low-income and middle-income countries: a pooled country analysis. Lancet 2013;382:417-25. doi:10.1016/S0140-6736(13)60993-9)

9. Regev RH, Lusky A, Dolfin T i sur. Excess mortality and morbitidy among small-for-gestational-age premature infants: a population based study. J Pediatr 2003;143:186-91. 
10. Calkins KL, Devaskar SU. Intrauterine growth retardation. U: Martin RJ, Fanaroff AA, Walsh MC. Ur. Fanaroff \& Martin's Neonatal-Perinatal Medicine. 10. Izd. Elsevier Saunders, Philadelphia, 2015:227-35.

11. Barker DJ, Hales CN, Fall CH i sur. Type 2 (non-insulin-dependent) diabetes mellitus, hypertension and hyperlipidaemia (syndrome X): relation to reduced fetal growth. Diabetologia 1993;36:62-7.

12. Tolsa CB, Zimine S, Warfield SK i sur. Early alteration of structural and functional brain development in premature infants born with intrauterine growth restriction. Pediatr Res. 2004;56:132-138.

13. Casey PH, Whiteside-Mandsell L, Barrett K i sur. Impact of prenatal and/or postnatal growth problems in low birth weight preterm infants on school-age outcomes: an 8-year longitudinal evaluation. Pediatrics. 2006;118:1078-1086.

14. Ehrenkranz RA, Dusick AM, Vohr BR i sur. Growth in the neonatal intensive care unit influences neurodevelopmental and growth outcomes of extremely low birth weight infants. Pediatrics. 2006;117:1253-1261.

15. Dutta S, Singh B, Chessell L, Wilson J i sur. Guidelines for feeding very low birth weight infants. Nutrients 2015;7:423-442.

16. Bazacliu C, Bhatia JJS. Parenteral nutrition. U: Polin RA, Yoder MC. Ur: Workbook in practical neonatology. Philadelphia, Elsevier Saunders 5. Izd. 2015:83-94.

17. Poindexter BB, Martin CR. Enteral nutrition. U: U: Polin RA, Yoder MC. Ur: Workbook in practical neonatology. Philadelphia, Elsevier Saunders 5. Izd. 2015:95-106. 